\title{
Antiemetic Effects of Cannabinoid Agonists in Nonhuman Primates
}

\author{
Lisa M. Wooldridge, Lipin Ji, Yingpeng Liu, Spyros P. Nikas, Alexandros Makriyannis, \\ Jack Bergman, and Brian D. Kangas \\ Department of Psychiatry, Harvard Medical School, Boston, Massachusetts (J.B., B.D.K.); Behavioral Biology Program, McLean \\ Hospital, Belmont, Massachusetts (L.M.W., J.B., B.D.K.); and Center for Drug Discovery, Northeastern University, Boston, \\ Massachusetts (L.J., Y.L., S.P.N., A.M.)
}

Received February 12, 2020; accepted June 18, 2020

\begin{abstract}
Attenuating emesis elicited by both disease and medical treatments of disease remains a critical public health challenge. Although cannabinergic medications have been used in certain treatment-resistant populations, Food and Drug Administrationapproved cannabinoid antiemetics are associated with undesirable side effects, including cognitive disruption, that limit their prescription. Previous studies have shown that a metabolically stable analog of the endocannabinoid anandamide, methanandamide (mAEA), may produce lesser cognitive disruption than that associated with the primary psychoactive constituent in cannabis, $\Delta^{9}$-tetrahydrocannabinol $\left(\Delta^{9}-\mathrm{THC}\right)$, raising the possibility that endocannabinoids may offer a therapeutic advantage over currently used medications. The present studies were conducted to evaluate this possibility by comparing the antiemetic effects of $\Delta^{9}$-THC $(0.032-0.1 \mathrm{mg} / \mathrm{kg})$ and mAEA (3.2$10.0 \mathrm{mg} / \mathrm{kg}$ ) against nicotine- and lithium chloride ( $\mathrm{LiCl}$ )-induced emesis and prodromal hypersalivation in squirrel monkeys. Pretreatment with $0.1 \mathrm{mg} / \mathrm{kg} \Delta^{9}$-THC blocked nicotine-induced emesis and reduced hypersalivation in all subjects and blocked $\mathrm{LiCl}$-induced emesis and reduced hypersalivation in three of four subjects. Pretreatment with $10 \mathrm{mg} / \mathrm{kg} \mathrm{mAEA}$ blocked nicotineinduced emesis in three of four subjects and $\mathrm{LiCl}$-induced
\end{abstract}

\section{Introduction}

Cannabinergic drugs are currently under investigation as pharmacotherapies for a variety of medical conditions. However, prior to the approval of Epidiolex for treatment-resistant seizures in 2018, the Food and Drug Administration (FDA) had approved only two cannabinoid pharmaceuticals: dronabinol (Marinol), a synthetic $\Delta^{9}$-tetrahydrocannabinol ( $\Delta^{9}$-THC), and nabilone (Cesamet), a structurally distinct synthetic cannabinoid agonist (Bedi et al., 2013). Both cannabinoids were initially approved explicitly for the treatment of refractory emesis and nausea secondary to chemotherapy for cancer, and their prescription is still limited to gastrointestinal disturbances during severe chronic illness (Seamon, 2006).

This research was supported by National Institutes of Health National Institute on Drug Abuse [Grant K01-DA035974] (to B.D.K.).

https://doi.org/10.1124/jpet.120.265710. emesis in one of four subjects and reduced both nicotine- and LiCl-induced hypersalivation. Antiemetic effects of $\Delta^{9}-\mathrm{THC}$ and mAEA were reversed by rimonabant pretreatment, providing verification of cannabinoid receptor type 1 mediation. These studies systematically demonstrate for the first time the antiemetic effects of cannabinoid agonists in nonhuman primates. Importantly, although $\Delta^{9}-\mathrm{THC}$ produced superior antiemetic effects, the milder cognitive effects of mAEA demonstrated in previous studies suggest that it may provide a favorable treatment option under clinical circumstances in which antiemetic efficacy must be balanced against side effect liability.

\section{SIGNIFICANCE STATEMENT}

Emesis has significant evolutionary value as a defense mechanism against ingested toxins; however, it is also one of the most common adverse symptoms associated with both disease and medical treatments of disease. The development of improved antiemetic pharmacotherapies has been impeded by a paucity of animal models. The present studies systematically demonstrate for the first time the antiemetic effects of the phytocannabinoid $\Delta^{9}$-tetrahydrocannabinol and endocannabinoid analog methanandamide in nonhuman primates.

ABBREVIATIONS: LiCl, lithium chloride; mAEA, methanandamide; $\Delta^{9}$-THC, $\Delta^{9}$-tetrahydrocannabinol CB1 cannabinoid receptor type 1.

Although $30 \%-50 \%$ of patients receiving highly emetogenic chemotherapy will experience refractory vomiting despite guideline-directed prophylaxis (Cohen et al., 2007; Tamura et al., 2017), the FDA-approved cannabinoids are not recommended as first-line antiemetics and appear sparsely as adjunctive therapies in clinical guidelines (Garcia and Shamliyan, 2018). This is because dronabinol and nabilone are associated with a higher rate of side effects than other antiemetics, including attention and memory impairment and dysphoria (Wesnes et al., 2010; Tafelski et al., 2016; Mathai et al., 2018; Schussel et al., 2018). Despite their unfavorable side effect profile, several studies have indicated that patients prefer cannabinoids over other antiemetics such as dopamine and serotonin antagonists (Einhorn et al., 1981; Ahmedzai et al., 1983; Smith et al., 2015). The reasons underlying this preference are unclear; however, there is evidence that cannabinoids are more effective at 
also attenuating nausea (Abrahamov et al., 1995; Meiri et al., 2007). Collectively, these studies confirm the medicinal utility of cannabinoids as antiemetic pharmacotherapies and suggest that the development of novel cannabinergic drugs with a reduced side effect profile would be clinically beneficial.

In addition to novel cannabinoid agonists, the development of improved cannabinergic pharmacotherapies has increasingly focused on enhancing endogenous activity. Indeed, emesis in shrews and ferrets can be blocked with endocannabinoids such as anandamide and 2-arachidonoylglycerol or by targeting catabolic enzymes (fatty acid amide hydrolase and monoacylglycerol lipase) to increase circulating endocannabinoid levels (Darmani, 2002; Sharkey et al., 2007; Parker et al., 2009; Sticht et al., 2013). In addition, separate studies have provided evidence that elevation of endocannabinoid activity has fewer cognition-impairing effects than the administration of synthetic agonists or phytocannabinoids such as $\Delta^{9}$-THC (Mechoulam and Parker, 2013; Kangas et al., 2016). Thus, increasing endocannabinoid activity might provide a novel avenue for development of cannabinergic antiemetic pharmacotherapies with fewer adverse effects, especially those related to cognition.

Unfortunately, the development of improved cannabinergic antiemetic pharmacotherapies has been impeded by a paucity of animal models. This is due to the fact that several of the most common laboratory animals, including the mouse, rat, guinea pig, and rabbit, are physically incapable of vomiting due to a complex array of neural and anatomic constraints (Horn et al., 2013). Most preclinical research in this area has thus been restricted to other species, such as the house musk shrew (Parker et al., 2004, 2009; Sticht et al., 2013; Rock et al., 2016), least shrew (Darmani, 2002; Ray et al., 2009), and ferret (Simoneau et al., 2001; Sharkey et al., 2007). Studies conducted in these subjects have provided important insights into emetic mechanisms. However, the shrew and ferret are relatively atypical laboratory animals that have not been extensively used for in vivo pharmacological studies. Thus, in the absence of data on possible side effects, it is difficult to assess the potential clinical value of novel antiemetics in these species.

Surprisingly, there are no published reports regarding antiemetic effects of cannabinoids in nonhuman primates. This is a curious gap considering the limitations of rodent subjects in emesis research and substantial in vivo cannabinoid research that has been conducted in nonhuman primates. In particular, squirrel monkeys, in which cannabinoids have been extensively studied (e.g., Branch et al., 1980; Tanda et al., 2000; Justinova et al., 2003, 2013; Solinas et al., 2007; Kangas and Bergman, 2012; Desai et al., 2013; Kangas et al., 2013, 2016; Leonard et al., 2017) and which have an emetic response, are highly suitable for evaluating the antiemetic effects of cannabinoids. The present studies therefore examined $\Delta^{9}$-THC, the primary psychoactive constituent in cannabis, and methanandamide [mAEA; $(R)-(+)$-arachidonyl$1^{\prime}$-hydroxy-2'-propylamide], a metabolically stable analog of the endocannabinoid anandamide, for their ability to block emesis and prodromal hypersalivation in the squirrel monkey. The antiemetic abilities of these drugs were examined by pretreating subjects prior to pharmacological challenges using two common emetic agents, nicotine and lithium chloride (LiCl). Finally, pretreatment with rimonabant [SR141716A, 5-(4-chlorophenyl)-1-(2,4-dichloro-phenyl)-4-methyl- $N$-(piperidin-1-yl)-1- $H$-pyrazole-3-carboxamide], the selective $\mathrm{CB}_{1}$ receptor antagonist, was assessed for its ability to reverse the antiemetic effects of $\Delta^{9}$-THC and mAEA to determine whether the observed effects were $\mathrm{CB}_{1}$-mediated.

\section{Methods}

Subjects. Five adult male squirrel monkeys (Saimiri sciureus) served in the present studies (one subject that served in the nicotine group did not serve in the $\mathrm{LiCl}$ group; nicotine, $n=4 ; \mathrm{LiCl}, n=4$ ). Four subjects were experimentally- and drug-naïve at the start of the study. The fifth subject previously served in a behavioral study examining opioid agonists but had not received drug treatment for 6 months prior to the present study. Subjects were housed in a temperature- and humidity-controlled vivarium with a 12-hour light/dark cycle (lights on at $7 \mathrm{AM}$ ), and environmental enrichment was provided daily. Subjects had unlimited access to water in the home cage and were maintained at approximate free-feeding weights by daily feedings of fresh fruit and nutritionally balanced high-protein biscuits (Monkey Chow; Purina, St. Louis, MO). Experimental sessions were conducted 5 days a week (Monday through Friday). Subjects were fed approximately 2 hours after each experimental session. The protocol for the present studies was approved by the Institutional Animal Care and Use Committee at McLean Hospital in a facility licensed by the US Department of Agriculture and in accordance with guidelines provided by the Committee on Care and Use of Laboratory Animals of the Institute of Laboratory Animals Resources, Commission on Life Sciences (National Research Council, 2011).

Apparatus. A custom-designed dual-compartment observation chamber was used to monitor two subjects simultaneously (Wooldridge and Kangas, 2019). Two clear Plexiglas cubes $(25 \times 25 \times 25 \mathrm{~cm})$ separated by an opaque Plexiglas divider resided in a light- and soundattenuating ventilated enclosure $(75 \times 60 \times 50 \mathrm{~cm})$. Mirrors were affixed to the walls and floor of the enclosure to provide a view of orofacial and abdominal movements when subjects were facing away from the observer. White noise was present in the experimental room to provide masking sound. Subjects were leashed but otherwise unrestrained within the observation chamber.

Experimental Procedures. Subjects were monitored continuously in the observation chamber during experimental sessions conducted at approximately the same time each day according to a preset plan. Instances of licking lasting longer than 2 seconds, chewing, drooling, foaming, and emesis were recorded as quantal measures (presence or absence) during each 1-minute bin. When hypersalivation was observed, duration was calculated by summing the total number of 1-minute bins in which at least one of the following responses occurred: licking, chewing, drooling, and foaming.

Effects of $\Delta^{\mathbf{9}}$-THC and mAEA on Nicotine- and LiCl-Induced Emesis and Hypersalivation. Drug testing sessions were conducted no more than once per week. Control sessions, in which $0.1-0.3 \mathrm{ml}$ of saline was administered, were conducted during intervening days to preclude the development of conditioned responses to injections or to the observation chamber.

The antiemetic effects of $\Delta^{9}$-THC and mAEA were studied in subjects treated with emetic doses of nicotine and $\mathrm{LiCl}$, both of which have been extensively used as emetic challenges in previous studies with shrews (Parker et al., 2004, 2009) and ferrets (Billig et al., 2001; $\mathrm{du}$ Sert et al., 2012). The doses of nicotine $(0.32 \mathrm{mg} / \mathrm{kg})$ and $\mathrm{LiCl}$ $(200 \mathrm{mg} / \mathrm{kg}$ ), as well as the duration of observation periods (20 and 60 minutes, respectively) and $\Delta^{9}$-THC and mAEA pretreatment times (30 minutes), were based on previous studies of nicotine, $\mathrm{LiCl}$, and cannabinoid agonists in squirrel monkeys (Justinova et al., 2013; Kangas et al., 2013, 2016; Leonard et al., 2017; Wooldridge and Kangas, 2019). First, the ability of $\Delta^{9}$-THC and mAEA to block nicotine-induced emesis and hypersalivation were determined by administering $\Delta^{9}$-THC ( 0.032 or $\left.0.1 \mathrm{mg} / \mathrm{kg}\right)$, mAEA ( 3.2 or $\left.10.0 \mathrm{mg} / \mathrm{kg}\right)$, 
A

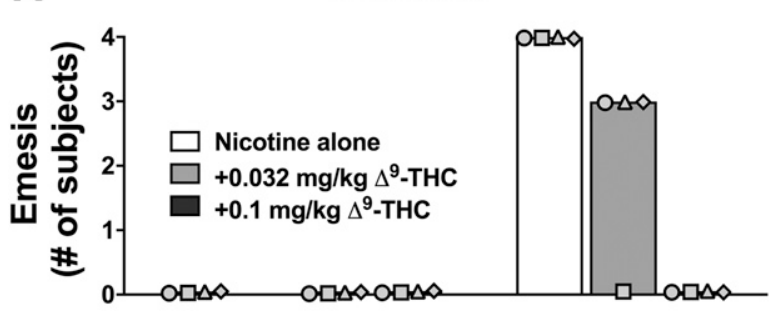

B

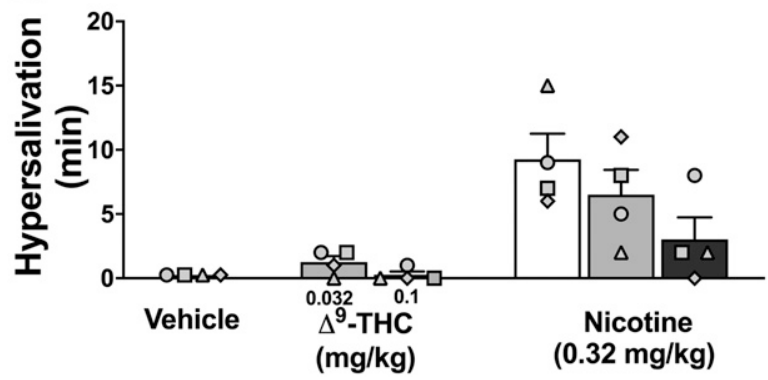

C Lithium Chloride
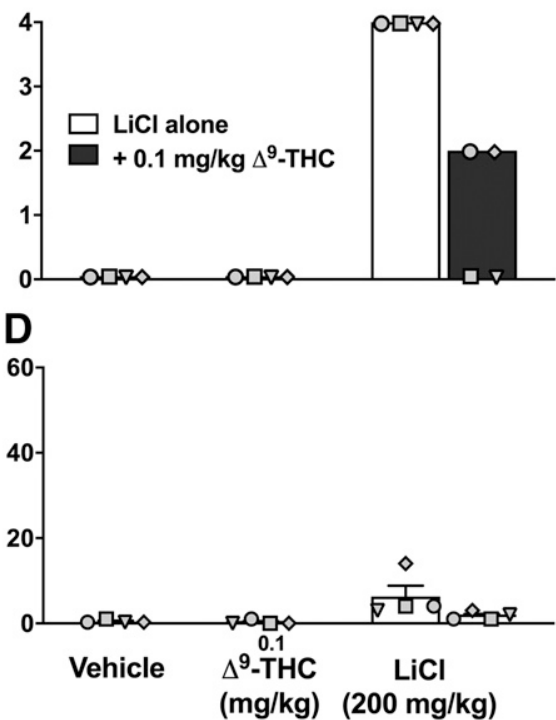

Fig. 1. Upper panels: number of subjects to exhibit an emetic episode after administration of vehicle or $0.032 \mathrm{or} 0.1 \mathrm{mg} / \mathrm{kg} \Delta^{9}$-THC alone and $30 \mathrm{minutes}$ before nicotine (A) or $\mathrm{LiCl}(\mathrm{C})$. Lower panels: mean ( \pm S.E.M.) duration of hypersalivation (minutes) after vehicle and $\Delta^{9}$-THC alone and 30 minutes before nicotine (B) or $\mathrm{LiCl}$ (D). Each symbol represents data from an individual subject. $n=4$.

or vehicle 30 minutes prior to treatment with saline or, in separate test sessions, a reliably emetic dose of nicotine $(0.32 \mathrm{mg} / \mathrm{kg})$. Next, the doses of $\Delta^{9}$-THC and mAEA that were most effective in preventing nicotine-induced emesis $(0.1$ and $10 \mathrm{mg} / \mathrm{kg}$, respectively) were examined further for their ability to modify LiCl-induced emesis. The antiemetic effects of $\Delta^{9}$-THC against nicotine and $\mathrm{LiCl}$ were tested in all subjects before those of mAEA. Finally, the involvement of $\mathrm{CB}_{1}$ receptor activity in the antiemetic effects of $\Delta^{9}$-THC and mAEA was studied by determining whether an antagonist dose of rimonabant in squirrel monkeys ( $0.32 \mathrm{mg} / \mathrm{kg}$; Kangas et al., 2013; Schindler et al., 2016) administered 30 minutes prior to $\Delta^{9}$-THC or mAEA could block the cannabinoid's effects. In these last experiments, the effects of rimonabant alone and prior to each agonist without nicotine were also assessed in separate test sessions by administering the $\mathrm{CB}_{1}$ antagonist and replacing injections of $\Delta^{9}$-THC, mAEA, and/or nicotine with injections of saline.

Drugs. (-)-Nicotine hydrogen tartrate was purchased from SigmaAldrich (St. Louis, MO) and was prepared in a $0.9 \%$ saline solution. The $\mathrm{pH}$ of the resulting solution was adjusted to $\sim 7.0$ with the addition of $0.1 \mathrm{~N}$ sodium hydroxide as needed. LiCl was purchased from Fisher Scientific (Hampton, NH) and was prepared in sterile water. $\Delta^{9}$-THC and rimonabant were provided by the National Institutes of Health National Institute on Drug Abuse Drug Supply Program (Rockville, MD). mAEA was synthesized by the present authors (L.J., Y.L.,
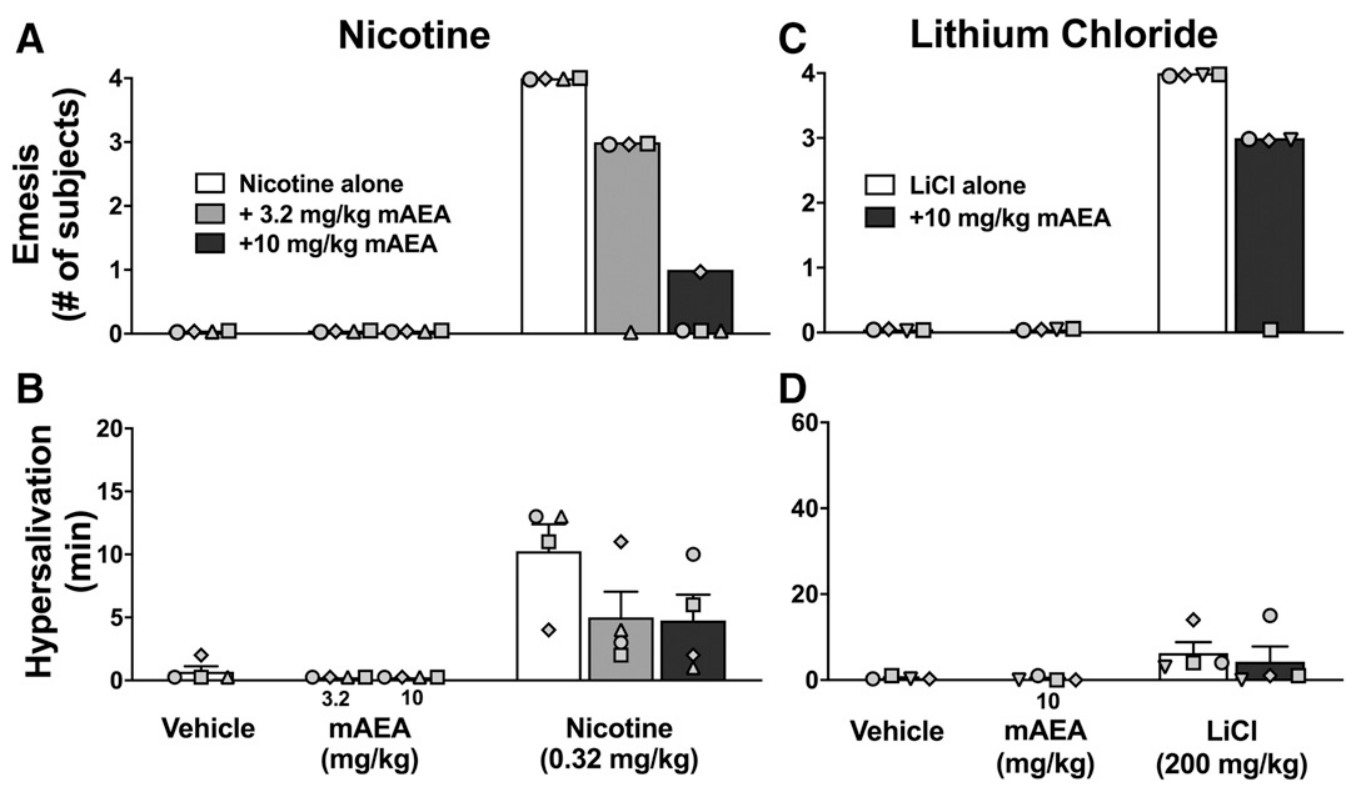

Fig. 2. Upper panels: number of subjects to exhibit an emetic episode after administration of vehicle, 3.2 , or $10 \mathrm{mg} / \mathrm{kg} \mathrm{mAEA}$ alone and $30 \mathrm{minutes}$ before nicotine (A) or $\mathrm{LiCl}(\mathrm{C})$. Lower panels: mean ( \pm S.E.M.) duration of hypersalivation (minutes) after vehicle and mAEA alone and 30 minutes before nicotine (B) or $\mathrm{LiCl}(\mathrm{D})$. Each symbol represents data from an individual subject. $n=4$. 
S.P.N., A.M.) at the Center for Drug Discovery at Northeastern University (Boston, MA) following previously described procedures (Abadji et al., 1994). The identity of the compound was confirmed via NMR spectra of mAEA recorded in deuterated chloroform on Varian $500\left({ }^{1} \mathrm{H}\right.$ at $\left.500 \mathrm{MHz}\right)$ and Bruker $400\left({ }^{13} \mathrm{C}\right.$ at $\left.100 \mathrm{MHz}\right)$ NMR spectrometers using previously reported procedures (Liu et al., 2018). mAEA purity was determined via liquid chromatography/mass spectrometry analysis using a Waters MicroMass ZQ system electrospray ionization with Waters-2525 binary gradient module coupled to a photodiode array detector (Waters-2996) and evaporative light scattering detector (Waters-2424) using an XTerra MS C18 $(5-\mu \mathrm{m}$ column, $4.6 \times 50 \mathrm{~mm}$, and acetonitrile/water) and was found to be $>97 \%$. $\Delta^{9}$-THC, mAEA, and rimonabant were prepared in a 20:20:60 mixture by volume of $95 \%$ ethanol, Tween 80 , and saline. All drugs and vehicle were administered via intramuscular injection in volumes of $0.4 \mathrm{ml} / \mathrm{kg}$ or less. Drug concentrations are expressed in terms of their free base.

\section{Results}

Effects of $\Delta^{9}$-THC on Nicotine- and LiCl-Induced Emesis and Hypersalivation. Figure 1 presents the effects of $\Delta^{9}$-THC pretreatment $(0.032$ and $0.1 \mathrm{mg} / \mathrm{kg})$ on druginduced emesis (Fig. 1, A and C) and hypersalivation (Fig. 1, $\mathrm{B}$ and D). Administration of vehicle, $0.032 \mathrm{mg} / \mathrm{kg} \Delta^{9}$-THC, or $0.1 \mathrm{mg} / \mathrm{kg} \Delta^{9}$-THC alone did not produce emesis in any subject. Pretreatment with $0.032 \mathrm{mg} / \mathrm{kg} \Delta^{9}$-THC blocked nicotineinduced emesis in one out of four subjects, and pretreatment with $0.1 \mathrm{mg} / \mathrm{kg} \Delta^{9}$-THC blocked nicotine-induced emesis in all four subjects (Fig. 1A). Administration of $\Delta^{9}$-THC alone produced minimal hypersalivation. Nicotine administration produced hypersalivation in each subject, with a mean duration of $8.8( \pm 1.55)$ minutes. Nicotine-induced hypersalivation was dose-dependently attenuated by $\Delta^{9}$-THC; $0.032 \mathrm{mg} / \mathrm{kg} \Delta^{9}$-THC decreased the mean duration of hypersalivation to $6.5( \pm 1.94)$ minutes, and $0.1 \mathrm{mg} / \mathrm{kg} \Delta^{9}$-THC decreased the mean duration to $3.0( \pm 1.73)$ minutes (Fig. 1B).

The most effective antiemetic dose of $\Delta^{9}$-THC tested against nicotine-induced emesis $(0.1 \mathrm{mg} / \mathrm{kg})$ was subsequently studied for its ability to attenuate LiCl-induced emesis (Fig. 1C) and hypersalivation (Fig. 1D). Pretreatment with $0.1 \mathrm{mg} / \mathrm{kg} \Delta^{9}$-THC blocked LiCl-induced emesis in two out of four subjects (Fig. 1C). $\mathrm{LiCl}$ alone produced a mean duration of hypersalivation of $6.3( \pm 2.59)$ minutes, and pretreatment with $0.1 \mathrm{mg} / \mathrm{kg}$ $\Delta^{9}$-THC reduced the duration to $1.8( \pm 0.48)$ minutes (Fig. 1D).

Effects of mAEA on Nicotine- and LiCl-Induced Emesis and Hypersalivation. Figure 2 presents the effects of mAEA pretreatment $(3.2$ and $10 \mathrm{mg} / \mathrm{kg})$ on drug-induced emesis (Fig. 2, A and C) and hypersalivation (Fig. 2, B and D). Administration of vehicle, $3.2 \mathrm{mg} / \mathrm{kg} \mathrm{mAEA}$, or $10 \mathrm{mg} / \mathrm{kg}$ mAEA did not produce emesis in any subject. Pretreatment with $3.2 \mathrm{mg} / \mathrm{kg}$ mAEA blocked nicotine-induced emesis in one out of four subjects, and pretreatment with $10 \mathrm{mg} / \mathrm{kg} \mathrm{mAEA}$ blocked nicotine-induced emesis in three out of four subjects (Fig. 2A). A higher dose of $17 \mathrm{mg} / \mathrm{kg}$ mAEA was tested in the fourth subject and also failed to block nicotine-induced emesis (data not shown). Pretreatment with mAEA also reduced nicotine-induced hypersalivation (Fig. 2B). Vehicle, $3.2 \mathrm{mg} / \mathrm{kg}$ $\mathrm{mAEA}$, or $10 \mathrm{mg} / \mathrm{kg} \mathrm{mAEA}$ did not produce hypersalivation when administered alone; however, pretreatment with $3.2 \mathrm{mg} / \mathrm{kg}$ mAEA reduced nicotine-induced hypersalivation from a mean duration of $8.8( \pm 1.55)$ minutes to $5.0( \pm 2.04)$, whereas $10 \mathrm{mg} / \mathrm{kg} \mathrm{mAEA}$ reduced hypersalivation to $4.8( \pm 2.06)$ minutes. In subsequent studies, pretreatment with $10 \mathrm{mg} / \mathrm{kg}$ mAEA blocked LiCl-induced emesis in only one of four subjects (Fig. 2C) and reduced LiCl-induced hypersalivation from a mean duration of $6.3( \pm 2.59)$ minutes to $4.3( \pm 3.59)$ minutes (Fig. 2D).

Effects of Rimonabant Pretreatment on $\Delta^{\mathbf{9}}$-THC and mAEA Antiemesis. Administration of $0.32 \mathrm{mg} / \mathrm{kg}$ rimonabant did not produce emesis or hypersalivation when administered alone or when administered before either $0.1 \mathrm{mg} / \mathrm{kg}$ $\Delta^{9}$-THC (Fig. 3A) or $10 \mathrm{mg} / \mathrm{kg} \mathrm{mAEA} \mathrm{(Fig.} \mathrm{3C).} \mathrm{However,} \mathrm{this}$ dose of rimonabant antagonized the previously observed antiemetic effects of $0.1 \mathrm{mg} / \mathrm{kg} \Delta^{9}$-THC in all subjects (Fig. 3A) and $10 \mathrm{mg} / \mathrm{kg}$ mAEA in three of four subjects (Fig. 3C) against nicotine-induced emesis. In addition, rimonabant pretreatment reversed the reductions in nicotineinduced hypersalivation after $\Delta^{9}$-THC from $3.0( \pm 1.73)$ minutes to $9.8( \pm 2.39)$ minutes (Fig. $3 \mathrm{~B})$ and after mAEA from $4.8( \pm 2.06)$ minutes to $9.0( \pm 1.6)$ minutes (Fig. 3D).

\section{Discussion}

The present studies compared the ability of $\Delta^{9}$-THC and mAEA to block nicotine- or LiCl-induced emesis and hypersalivation in the squirrel monkey. $\Delta^{9}$-THC was able to block nicotine-induced emesis and hypersalivation in all subjects tested and LiCl-induced emesis in some, but not all, subjects. Like $\Delta^{9}$-THC, mAEA was able to block nicotine- and LiClinduced emesis and reduce hypersalivation. However, these effects were not evident in all subjects, regardless of whether the emetic agent was nicotine or LiCl. Finally, rimonabant pretreatment reversed the antiemetic effects of both $\Delta^{9}$-THC and mAEA, providing evidence that their antiemetic effects are mediated via $\mathrm{CB}_{1}$ receptor mechanisms. These findings are consistent with previous work demonstrating $\mathrm{CB}_{1}$-mediated antiemetic effects of $\Delta^{9}$-THC and mAEA against a variety of emetic stimuli in the least shrew (Darmani, 2002) and ferret (Van Sickle et al., 2001).

Notably, $\Delta^{9}$-THC and mAEA were more effective at blocking nicotine-induced than LiCl-induced emesis. Both emetics have been shown to reliably produce emesis in several species, including the squirrel monkey, but may act via different mechanisms (Lee et al., 1978; Beleslin and Krstic, 1987; Billig et al., 2001; Parker et al., 2004, 2009; Wooldridge and Kangas, 2019). Nicotine primarily acts at nicotinic receptors in the area postrema, or the "chemoreceptor trigger zone," of the central nervous system. The blood-brain barrier in this region of the medulla is relatively permeable, permitting the detection of circulating emetogens in the bloodstream (Beleslin and Krstic, 1987). Although the mechanisms by which $\mathrm{LiCl}$ produces emesis are less thoroughly understood, they are thought to involve both central and peripheral actions. Centrally, $\mathrm{LiCl}$ is thought to act in the area postrema (Fox et al., 1990; Spencer et al., 2012) and, via elevation of serotonin release, in the interoceptive insular cortex (Limebeer et al., 2018), a region implicated in nausea in humans (Penfield and Faulk, 1955; Napadow et al., 2013; Sclocco et al., 2016) and rats (Contreras et al., 2007; Sticht et al., 2016). Peripherally, $\mathrm{LiCl}$ is thought to act at the splanchnic and vagus nerves in the gut (Yamamoto et al., 1992; Horn et al., 2014). In this regard, previous work in the least shrew has suggested that $\Delta^{9}$-THC may more potently block centrally-mediated than peripherally-mediated emesis (Darmani and Johnson, 2004). 
Thus, it is possible that the greater effectiveness of both cannabinoid agonists against nicotine-induced than LiClinduced emesis in the present studies is related to ineffectiveness against LiCl's peripheral actions. The evaluation of higher doses that might also block such peripheral actions could address this possibility.

The antiemetic effects of both $\Delta^{9}$-THC and mAEA in the present study were reversed by pretreatment with the selective $\mathrm{CB}_{1}$ receptor antagonist rimonabant, indicating that their effects are mediated by $\mathrm{CB}_{1}$ receptors. This result is consistent with previous studies demonstrating that $\Delta^{9}$-THC and mAEA act at $\mathrm{CB}_{1}$ receptors to block the emetic reflex initiated in the brainstem (Van Sickle et al., 2001, 2005). Indeed, cannabinoid receptors are ubiquitous throughout both the gastrointestinal tract and the brainstem areas responsible for the production of emesis (Darmani, 2010). Although $\mathrm{CB}_{2}$ receptor activation is also associated with the antiemetic effects of certain cannabinoid agonists (Van Sickle et al., 2005; Rock et al., 2016), the selective blockade of $\mathrm{CB}_{2}$ receptors with AM630 or SR144528 has been shown to be insufficient to block the antiemetic effects of $\Delta^{9}$-THC or anandamide in the ferret (Van Sickle et al., 2005) and least shrew (Darmani et al., 2007).

Both $\Delta^{9}$-THC and, to a lesser extent, mAEA also reduced the hypersalivation that accompanied nicotine- or LiCl-induced emesis, and consistent with the involvement of $\mathrm{CB}_{1}$ receptor mechanisms, these cannabinergic effects could be blocked by rimonabant. Hypersalivation is thought to be a prodromal sign that often accompanies and worsens the subjective experience of emesis (Sanger and Andrews, 2006; Kenward et al., 2015; Wooldridge and Kangas, 2019). The ability of cannabinoid agonists to abate hypersalivation may therefore be a means of alleviating such distress and, consequently, reflects a desirable feature of their medicinal value.
In these studies, $\Delta^{9}$-THC consistently produced a more robust antiemetic effect than did mAEA. The difference in antiemetic activity may reflect a difference in $\mathrm{CB}_{1}$ receptor efficacy; that is, although $\Delta^{9}$-THC and mAEA are both generally considered $\mathrm{CB}_{1}$ receptor partial agonists, $\Delta^{9}$-THC may have greater $\mathrm{CB}_{1}$ efficacy than either mAEA or anandamide (Brodkin and Moerschbaecher, 1997; Järbe et al., 1998; Desai et al., 2013). Alternatively, the engagement of noncannabinoid neurotransmitter systems may account for the difference in antiemetic effects of the two cannabinoid agonists. For example, $\Delta^{9}$-THC primarily acts at cannabinoid receptors (de Petrocellis et al., 2011), whereas the endocannabinoids, including anandamide, have other targets, including the capsaicin-sensitive transient receptor potential vanilloid type 1 receptor, another channel associated with the production of emesis (Andrews and Bhandari, 1993; Andrews et al., 2000; Yamakuni et al., 2002; Ross, 2003; Chu et al., 2010).

As the antiemetic effects of $\Delta^{9}$-THC were examined first in all subjects, it is possible that the difference in effectiveness reflects tolerance to the effects of the cannabinoid agonists. However, tolerance to the physiologic, rate-decreasing, and cognition-impairing effects of cannabinoids in laboratory animals typically requires several consecutive days of highdose treatment [reviewed in González et al. (2005)], whereas cannabinergic drugs in the present studies were administered no more than once per week over a period of several months. Subchronic or chronic treatment with cannabinergic drugs has not yet been examined in animal models of emesis, but tolerance to nabilone or dronabinol has not been reported over a typical course of chemotherapy in clinical studies (Meiri et al., 2007; Ware et al., 2008; May and Glode, 2016). Nevertheless, further studies are needed to systematically evaluate the development of tolerance over the treatment
A

$\Delta^{9}$-THC

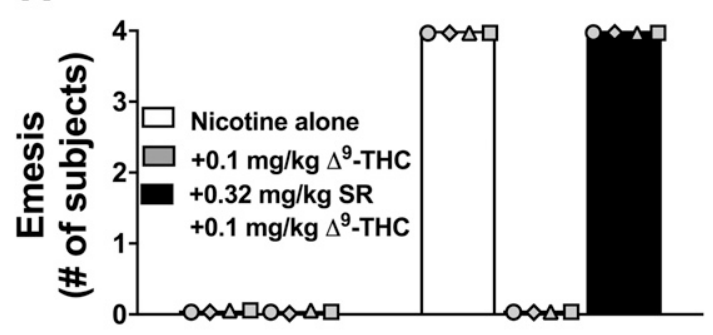

B

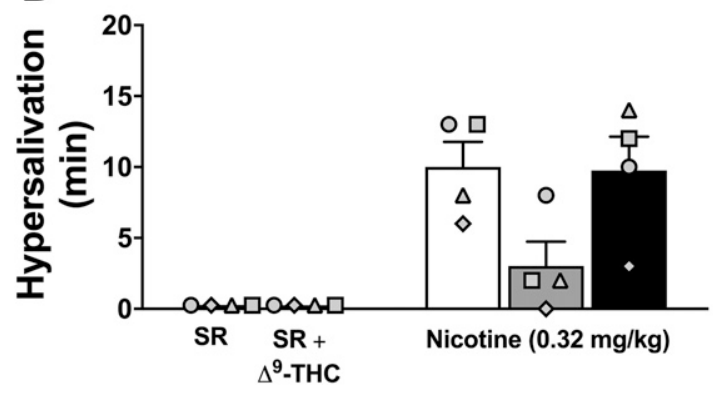

C

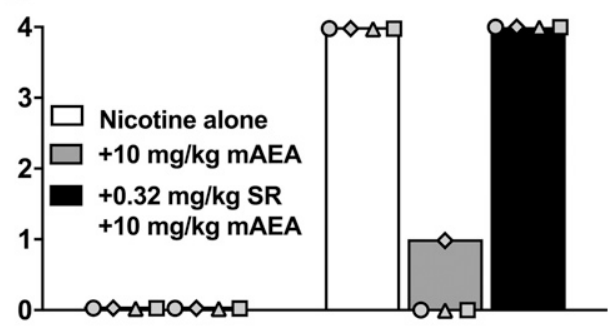

D

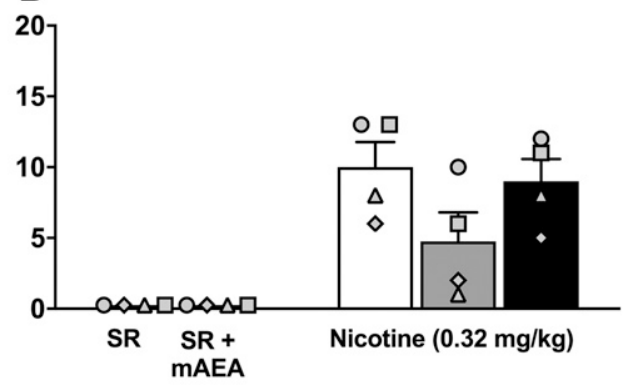

Fig. 3. Upper panels: effects of $0.32 \mathrm{mg} / \mathrm{kg}$ rimonabant (SR) on the ability of $0.1 \mathrm{mg} / \mathrm{kg} \Delta^{9}$-THC (A) or $10 \mathrm{mg} / \mathrm{kg} \mathrm{mAEA}$ (C) to block nicotine-induced emesis. Lower panels: effects of $0.32 \mathrm{mg} / \mathrm{kg}$ rimonabant (SR) on the ability of $0.1 \mathrm{mg} / \mathrm{kg} \Delta^{9}$-THC (B) or $10 \mathrm{mg} / \mathrm{kg} \mathrm{mAEA}$ (D) to reduce nicotine-induced hypersalivation. Rimonabant was administered 60 minutes before nicotine, and $\Delta^{9}$-THC or mAEA were administered 30 minutes before nicotine. Each symbol represents data from an individual subject. $n=4$. 
TABLE 1

Comparison of the maximally effective antiemetic doses of $\Delta^{9}$-THC and mAEA derived from present findings, and cognition-impairing doses of $\Delta^{9}$-THC and mAEA on touchscreen-based assays of learning (RA), cognitive flexibility (DR), short-term memory (DMTS), and sustained attention (PVT) derived from Kangas et al. (2016)

\begin{tabular}{|c|c|c|c|c|c|}
\hline & \multirow[b]{2}{*}{ Maximally Effective Antiemetic Dose } & \multicolumn{4}{|c|}{ Lowest Dose that Disrupted Cognitive Behavior } \\
\hline & & $\mathrm{RA}$ & $\mathrm{DR}$ & DMTS & PVT \\
\hline$\Delta^{9}$-THC & $0.1 \mathrm{mg} / \mathrm{kg}$ & $0.1 \mathrm{mg} / \mathrm{kg}$ & $0.1 \mathrm{mg} / \mathrm{kg}$ & $0.1 \mathrm{mg} / \mathrm{kg}$ & $0.32 \mathrm{mg} / \mathrm{kg}$ \\
\hline
\end{tabular}

DMTS, delayed matching-to-sample; DR, discrimination reversal; PVT, psychomotor vigilance; RA, repeated acquisition.

periods that would be necessary in subchronic or chronic regimens in clinical settings.

Finally, although a complete antiemetic effect was not achieved with doses of mAEA tested here against either emetic, this compound-or related endocannabinoid derivatives-may offer some translational advantage over $\Delta^{9}$ THC, in particular with regard to cognition-impairing side effects. For example, Kangas et al. (2016) compared the cognition-impairing effects of several cannabinoid agonists, including $\Delta^{9}$-THC and mAEA, in similarly aged adult male squirrel monkeys and found that antiemetic doses of $\Delta^{9}$-THC identified in the present study produced considerably more pronounced cognition-impairing effects than did the most effective dose of mAEA identified here (see Table 1). Specifically, $0.1 \mathrm{mg} / \mathrm{kg} \Delta^{9}$-THC disrupted performance across a battery of cognitive tasks designed to assay learning (repeated acquisition), cognitive flexibility (discrimination reversal), and working memory (delayed matching-to-sample). In contrast, $10 \mathrm{mg} / \mathrm{kg} \mathrm{mAEA}$ was not associated with any cognition-impairing effects yet, in the present study, produced moderate antiemetic effects. Collectively, these data suggest that mAEA (or, possibly, other endocannabinoid derivatives) may offer a balance between moderate yet clinically beneficial antiemetic efficacy independent of cognition-impairing effects. Such effects are particularly important to consider in the development of antiemetics, as many of the conditions for which novel antiemetic treatments are needed, most notably chemotherapy, are also associated with distressing disruptions in cognitive function-colloquially referred to as "chemo brain" or "chemo fog" (Asher, 2011; Janelsins et al., 2017).

In summary, the present studies systematically demonstrate for the first time that the phytocannabinoid $\Delta^{9}$-THC and the endocannabinoid analog mAEA produce antiemetic effects in nonhuman primates. Future studies are necessary to confirm the utility of cannabinergic antiemetics against chemotherapy-induced nausea and vomiting, as well as to evaluate the possibility of tolerance to their antiemetic effects over treatment periods that would be clinically necessary. Such studies should also establish the ability of these cannabinergic compounds to limit anticipatory nausea and vomiting, which often develop during the course of emetic chemotherapy. Finally, methods of engaging the endocannabinoid system, such as exogenous administration of other endocannabinoids (e.g., 2-arachidonoylglycerol) or by inhibition of their metabolic enzymes (e.g., fatty acid amide hydrolase, monoacylglycerol lipase), should be examined, ideally to identify compounds with maximal antiemetic and antinausea effects and minimal cognition-impairing side effects.

\section{Acknowledgments}

The authors thank Roger Spealman for comments on a previous version of this manuscript.

\section{Authorship Contributions}

Participated in research design: Wooldridge, Bergman, Kangas.

Conducted experiments: Wooldridge.

Contributed new reagents or analytic tools: Ji, Liu, Nikas, Makriyannis.

Performed data analysis: Wooldridge, Kangas.

Wrote or contributed to the writing of the manuscript: Wooldridge, Bergman, Kangas.

\section{References}

Abadji V, Lin S, Taha G, Griffin G, Stevenson LA, Pertwee RG, and Makriyannis A (1994) (R)-methanandamide: a chiral novel anandamide possessing higher potency and metabolic stability. J Med Chem 37:1889-1893.

Abrahamov A, Abrahamov A, and Mechoulam R (1995) An efficient new cannabinoid antiemetic in pediatric oncology. Life Sci 56:2097-2102.

Ahmedzai S, Carlyle DL, Calder IT, and Moran F (1983) Anti-emetic efficacy and toxicity of nabilone, a synthetic cannabinoid, in lung cancer chemotherapy. $\mathrm{Br}$ $J$ Cancer 48:657-663.

Andrews PL and Bhandari P (1993) Resinferatoxin, an ultrapotent capsaicin analogue, has anti-emetic properties in the ferret. Neuropharmacology 32:799-806.

Andrews PL, Okada F, Woods AJ, Hagiwara H, Kakaimoto S, Toyoda M, and Matsuki N (2000) The emetic and anti-emetic effects of the capsaicin analogue resiniferatoxin in Suncus murinus, the house musk shrew. $\mathrm{Br} J$ Pharmacol 130: 1247-1254.

Asher A (2011) Cognitive dysfunction among cancer survivors. Am J Phys Med Rehabil 90 (5 Suppl 1):S16-S26.

Bedi G, Cooper ZD, and Haney M (2013) Subjective, cognitive and cardiovascular dose-effect profile of nabilone and dronabinol in marijuana smokers. Addict Biol 18:872-881.

Beleslin DB and Krstić SK (1987) Further studies on nicotine-induced emesis: nicotinic mediation in area postrema. Physiol Behav 39:681-686.

Billig I, Yates BJ, and Rinaman L (2001) Plasma hormone levels and central c-Fos expression in ferrets after systemic administration of cholecystokinin. Am J Physiol Regul Integr Comp Physiol 281:R1243-R1255.

Branch MN, Dearing ME, and Lee DM (1980) Acute and chronic effects of delta 9tetrahydrocannabinol on complex behavior of squirrel monkeys. Psychopharmacology (Berl) 71:247-256.

Brodkin J and Moerschbaecher JM (1997) SR141716A antagonizes the disruptive effects of cannabinoid ligands on learning in rats. $J$ Pharmacol Exp Ther 282: 1526-1532.

Chu KM, Ngan MP, Wai MK, Yeung CK, Andrews PL, Percie du Sert N, and Rudd JA (2010) Olvanil: a non-pungent TRPV1 activator has anti-emetic properties in the ferret. Neuropharmacology 58:383-391.

Cohen L, de Moor CA, Eisenberg P, Ming EE, and Hu H (2007) Chemotherapyinduced nausea and vomiting: incidence and impact on patient quality of life at community oncology settings. Support Care Cancer 15:497-503.

Contreras M, Ceric F, and Torrealba F (2007) Inactivation of the interoceptive insula disrupts drug craving and malaise induced by lithium. Science 318:655-658.

Darmani NA (2002) The potent emetogenic effects of the endocannabinoid, 2-AG (2arachidonoylglycerol) are blocked by $\operatorname{delta}(9)$-tetrahydrocannabinol and other cannnabinoids. J Pharmacol Exp Ther 300:34-42.

Darmani NA (2010) Mechanisms of broad-spectrum antiemetic efficacy of cannabinoids against chemotherapy-induced acute and delayed vomiting. Pharmaceuticals (Basel) 3:2930-2955.

Darmani NA, Janoyan JJ, Crim J, and Ramirez J (2007) Receptor mechanism and antiemetic activity of structurally-diverse cannabinoids against radiation-induced emesis in the least shrew. Eur J Pharmacol 563:187-196.

Darmani NA and Johnson JC (2004) Central and peripheral mechanisms contribute to the antiemetic actions of delta-9-tetrahydrocannabinol against 5-hydroxytryptophan-induced emesis. Eur J Pharmacol 488:201-212.

De Petrocellis L, Ligresti A, Moriello AS, Allarà M, Bisogno T, Petrosino S, Stott CG, and Di Marzo V (2011) Effects of cannabinoids and cannabinoid-enriched Cannabis extracts on TRP channels and endocannabinoid metabolic enzymes. $\mathrm{Br}$ J Pharmacol 163:1479-1494.

Desai RI, Thakur GA, Vemuri VK, Bajaj S, Makriyannis A, and Bergman J (2013) Analysis of tolerance and behavioral/physical dependence during chronic CB1 
agonist treatment: effects of CB1 agonists, antagonists, and noncannabinoid drugs. J Pharmacol Exp Ther 344:319-328.

du Sert NP, Holmes AM, Wallis R, and Andrews PL (2012) Predicting the emetic liability of novel chemical entities: a comparative study. $\mathrm{Br} J$ Pharmacol 165: 1848-1867.

Einhorn LH, Nagy C, Furnas B, and Williams SD (1981) Nabilone: an effective antiemetic in patients receiving cancer chemotherapy. $J$ Clin Pharmacol 21:64S-69S.

Fox RA, Corcoran M, and Brizzee KR (1990) Conditioned taste aversion and motion sickness in cats and squirrel monkeys. Can J Physiol Pharmacol 68:269-278.

Garcia JM and Shamliyan TA (2018) Cannabinoids in patients with nausea and vomiting associated with malignancy and its treatments. Am J Med 131: 755-759.e2.

González S, Cebeira M, and Fernández-Ruiz J (2005) Cannabinoid tolerance and dependence: a review of studies in laboratory animals. Pharmacol Biochem Behav 81:300-318.

Horn CC, Kimball BA, Wang H, Kaus J, Dienel S, Nagy A, Gathright GR, Yates BJ, and Andrews PL (2013) Why can't rodents vomit? A comparative behavioral, anatomical, and physiological study. PLoS One 8:e60537.

Horn CC, Meyers K, and Oberlies N (2014) Musk shrews selectively bred for motion sickness display increased anesthesia-induced vomiting. Physiol Behav 124: 129-137.

Janelsins MC, Heckler CE, Peppone LJ, Kamen C, Mustian KM, Mohile SG, Magnuson A, Kleckner IR, Guido JJ, Young KL, et al. (2017) Cognitive complaints in survivors of breast cancer after chemotherapy compared with age-matched controls: an analysis from a nationwide, multicenter, prospective longitudinal study. $J$ Clin Oncol 35:506-514

Järbe TU, Lamb RJ, Makriyannis A, Lin S, and Goutopoulos A (1998) $\Delta^{9}$-THC training dose as a determinant for $(R)$-methanandamide generalization in rats Psychopharmacology (Berl) 140:519-522.

Justinova Z, Mascia P, Wu HQ, Secci ME, Redhi GH, Panlilio LV, Scherma M, Barnes C, Parashos A, Zara T, et al. (2013) Reducing cannabinoid abuse and preventing relapse by enhancing endogenous brain levels of kynurenic acid. Nat Neurosci 16 $1652-1661$

Justinova Z, Tanda G, Redhi GH, and Goldberg SR (2003) Self-administration of delta9-tetrahydrocannabinol (THC) by drug naive squirrel monkeys. Psychopharmacology (Berl) 169:135-140.

Kangas BD and Bergman J (2012) A novel touch-sensitive apparatus for behavioral studies in unrestrained squirrel monkeys. J Neurosci Methods 209:331-336.

Kangas BD, Delatte MS, Vemuri VK, Thakur GA, Nikas SP, Subramanian KV, Shukla VG, Makriyannis A, and Bergman J (2013) Cannabinoid discrimination and antagonism by $\mathrm{CB}(1)$ neutral and inverse agonist antagonists. $J$ Pharmacol Exp Ther 344:561-567.

Kangas BD, Leonard MZ, Shukla VG, Alapafuja SO, Nikas SP, Makriyannis A and Bergman J (2016) Comparisons of $\Delta 9$-Tetrahydrocannabinol and anandamide on a battery of cognition-related behavior in nonhuman primates. J Pharmacol Exp Ther 357:125-133

Kenward H, Pelligand L, Savary-Bataille K, and Elliott J (2015) Nausea: current knowledge of mechanisms, measurement and clinical impact. Vet $J$ 203:36-43.

Lee HK, Chung PM, and Wang SC (1978) Mechanism of antiemetic action of penfluridol in the dog. Eur J Pharmacol 53:29-38.

Leonard MZ, Alapafuja SO, Ji L, Shukla VG, Liu Y, Nikas SP, Makriyannis A Bergman J, and Kangas BD (2017) Cannabinoid $\mathrm{CB}_{1}$ discrimination: Effects of endocannabinoids and catabolic enzyme inhibitors. J Pharmacol Exp Ther 363: 314-323.

Limebeer CL, Rock EM, Sharkey KA, and Parker LA (2018) Nausea-induced 5-HT release in the interoceptive insular cortex and regulation by monoacylglycerol lipase (MAGL) inhibition and cannabidiol. eNeuro 5 (ENEURO.0256-18.2018).

Liu Y, Ji L, Eno M, Kudalkar S, Li AL, Schimpgen M, Benchama O, Morales P, Xu S, Hurst D, et al. (2018) ( R)- N-(1-methyl-2-hydroxyethyl)-13-( S)-methyl-arachidonamide (AMG315): a novel chiral potent endocannabinoid ligand with stability to metabolizing enzymes. $J$ Med Chem 61:8639-8657.

Mathai DS, Holst M, Rodgman C, Haile CN, Keller J, Hussain MZ, Kosten TR, Newton TF, and Verrico CD (2018) Guanfacine attenuates adverse effects of dronabinol (THC) on working memory in adolescent-onset heavy cannabis users: a pilot study. $J$ Neuropsychiatry Clin Neurosci 30:66-76.

May MB and Glode AE (2016) Dronabinol for chemotherapy-induced nausea and vomiting unresponsive to antiemetics. Cancer Manag Res 8:49-55.

Mechoulam R and Parker LA (2013) The endocannabinoid system and the brain Annu Rev Psychol 64:21-47.

Meiri E, Jhangiani H, Vredenburgh JJ, Barbato LM, Carter FJ, Yang HM, and Baranowski V (2007) Efficacy of dronabinol alone and in combination with ondansetron versus ondansetron alone for delayed chemotherapy-induced nausea and vomiting. Curr Med Res Opin 23:533-543.

Napadow V, Sheehan JD, Kim J, Lacount LT, Park K, Kaptchuk TJ, Rosen BR, and Kuo B (2013) The brain circuitry underlying the temporal evolution of nausea in humans. Cereb Cortex 23:806-813.

National Research Council (2011) Guidelines for the Care and Use of Laboratory Animals, 8th ed., The National Academies Press, Washington, DC.

Parker LA, Kwiatkowska M, Burton P, and Mechoulam R (2004) Effect of cannabinoids on lithium-induced vomiting in the Suncus murinus (house musk shrew) Psychopharmacology (Berl) 171:156-161.

Parker LA, Limebeer CL, Rock EM, Litt DL, Kwiatkowska M, and Piomelli D (2009) The FAAH inhibitor URB-597 interferes with cisplatin- and nicotine-induced vomiting in the Suncus murinus (house musk shrew). Physiol Behav 97:121-124.

Penfield W and Faulk ME Jr. (1955) The insula; further observations on its function. Brain 78:445-470.
Ray AP, Griggs L, and Darmani NA (2009) Delta 9-tetrahydrocannabinol suppresses vomiting behavior and Fos expression in both acute and delayed phases of cisplatin-induced emesis in the least shrew. Behav Brain Res 196:30-36.

Rock EM, Boulet N, Limebeer CL, Mechoulam R, and Parker LA (2016) Cannabinoid 2 (CB2) receptor agonism reduces lithium chloride-induced vomiting in Suncus murinus and nausea-induced conditioned gaping in rats. Eur J Pharmacol 786: 94-99.

Ross RA (2003) Anandamide and vanilloid TRPV1 receptors. Br J Pharmacol 140: 790-801.

Sanger GJ and Andrews PLR (2006) Treatment of nausea and vomiting: gaps in our knowledge. Auton Neurosci 129:3-16.

Schindler CW, Redhi GH, Vemuri K, Makriyannis A, Le Foll B, Bergman J, Goldberg SR, and Justinova Z (2016) Blockade of nicotine and cannabinoid reinforcement and relapse by a cannabinoid CB1-receptor neutral antagonist AM4113 and inverse agonist rimonabant in squirrel monkeys. Neuropsychopharmacology 41 $2283-2293$

Schussel V, Kenzo L, Santos A, Bueno J, Yoshimura E, de Oliveira Cruz Latorraca C, Pachito DV, and Riera R (2018) Cannabinoids for nausea and vomiting related to chemotherapy: overview of systematic reviews. Phytother Res 32:567-576.

Sclocco R, Kim J, Garcia RG, Sheehan JD, Beissner F, Bianchi AM, Cerutti S, Kuo B, Barbieri R, and Napadow V (2016) Brain circuitry supporting multi-organ autonomic outflow in response to nausea. Cereb Cortex 26:485-497.

Seamon MJ (2006) The legal status of medical marijuana. Ann Pharmacother 40 $2211-2215$

Sharkey KA, Cristino L, Oland LD, Van Sickle MD, Starowicz K, Pittman QJ, Guglielmotti V, Davison JS, and Di Marzo V (2007) Arvanil, anandamide and $\mathrm{N}$-arachidonoyl-dopamine (NADA) inhibit emesis through cannabinoid CB1 and vanilloid TRPV1 receptors in the ferret. Eur J Neurosci 25:2773-2782.

Simoneau II, Hamza MS, Mata HP, Siegel EM, Vanderah TW, Porreca F, Makriyannis A, and Malan TP Jr. (2001) The cannabinoid agonist WIN55,212-2 suppresses opioid-induced emesis in ferrets. Anesthesiology 94:882-887.

Smith LA, Azariah F, Lavender VTC, Stoner NS, and Bettiol S (2015) Cannabinoids for nausea and vomiting in adults with cancer receiving chemotherapy. Cochrane Database Syst Rev 2015:CD009464.

Solinas M, Tanda G, Justinova Z, Wertheim CE, Yasar S, Piomelli D, Vadivel SK, Makriyannis A, and Goldberg SR (2007) The endogenous cannabinoid anandamide produces delta-9-tetrahydrocannabinol-like discriminative and neurochemical effects that are enhanced by inhibition of fatty acid amide hydrolase but not by inhibition of anandamide transport. J Pharmacol Exp Ther 321:370-380.

Spencer CM, Eckel LA, Nardos R, and Houpt TA (2012) Area postrema lesions attenuate LiCl-induced c-Fos expression correlated with conditioned taste aversion learning. Physiol Behav 105:151-160.

Sticht MA, Limebeer CL, Rafla BR, Abdullah RA, Poklis JL, Ho W, Niphakis MJ, Cravatt BF, Sharkey KA, Lichtman AH, et al. (2016) Endocannabinoid regulation of nausea is mediated by 2 -arachidonoylglycerol (2-AG) in the rat visceral insular cortex. Neuropharmacology 102:92-102.

Sticht MA, Rock EM, and Parker LA (2013) 2-arachidonoylglycerol interferes with lithium-induced vomiting in the house musk shrew, Suncus murinus. Physiol Behav 120:228-232.

Tafelski S, Häuser W, and Schäfer M (2016) Efficacy, tolerability, and safety of cannabinoids for chemotherapy-induced nausea and vomiting--a systematic review of systematic reviews. Schmerz 30:14-24.

Tamura K, Aiba K, Saeki T, Nakanishi Y, Kamura T, Baba H, Yoshida K, Yamamoto N, Kitagawa Y, Maehara Y, et al.; CINV Study Group of Japan (2017) Breakthrough chemotherapy-induced nausea and vomiting: report of a nationwide survey by the CINV Study Group of Japan. Int J Clin Oncol 22:405-412.

Tanda G, Munzar P, and Goldberg SR (2000) Self-administration behavior is maintained by the psychoactive ingredient of marijuana in squirrel monkeys. Nat Neurosci 3:1073-1074.

Van Sickle MD, Duncan M, Kingsley PJ, Mouihate A, Urbani P, Mackie K, Stella N, Makriyannis A, Piomelli D, Davison JS, et al. (2005) Identification and functional characterization of brainstem cannabinoid $\mathrm{CB}_{2}$ receptors. Science 310:329-332.

Van Sickle MD, Oland LD, Ho W, Hillard CJ, Mackie K, Davison JS, and Sharkey KA (2001) Cannabinoids inhibit emesis through CB1 receptors in the brainstem of the ferret. Gastroenterology 121:767-774.

Ware MA, Daeninck P, and Maida V (2008) A review of nabilone in the treatment of chemotherapy-induced nausea and vomiting. Ther Clin Risk Manag 4:99-107.

Wesnes KA, Annas P, Edgar CJ, Deeprose C, Karlsten R, Philipp A, Kalliomäki J, and Segerdahl M (2010) Nabilone produces marked impairments to cognitive function and changes in subjective state in healthy volunteers. J Psychopharmacol 24:1659-1669.

Wooldridge LM and Kangas BD (2019) An assay of drug-induced emesis in the squirrel monkey (Saimiri sciureus). J Med Primatol 48:236-243.

Yamakuni H, Sawai-Nakayama H, Imazumi K, Maeda Y, Matsuo M, Manda T, and Mutoh S (2002) Resiniferatoxin antagonizes cisplatin-induced emesis in dogs and ferrets. Eur J Pharmacol 442:273-278.

Yamamoto T, Shimura T, Sako N, Azuma S, Bai WZ, and Wakisaka S (1992) C-fos expression in the rat brain after intraperitoneal injection of lithium chloride. Neuroreport 3:1049-1052.

Address correspondence to: Dr. Brian D. Kangas, Behavioral Biology Program, Harvard Medical School, McLean Hospital, 115 Mill Street, Belmont, MA 02478. E-mail: bkangas@mclean.harvard.edu 